\title{
An Introduction: Legal Regulation of the Digital Economy and Digital Relations in the $21^{\text {st }}$ Century
}

\author{
Aida Guliyeva ${ }^{1}$ Elena Korneeva ${ }^{2,3}$ Wadim Strielkowski ${ }^{4, *}$ \\ ${ }^{1}$ Azerbaijan State University of Economics, Baku 1001, Azerbaijan \\ ${ }^{2}$ Financial University under the Government of the Russian Federation, Moscow 125167, Russian Federation \\ ${ }^{3}$ Togliatti State University, Togliatti 445667, Russian Federation \\ ${ }^{4}$ Prague Institute for Qualification Enhancement, Prague 15200, Czech Republic \\ "Corresponding author.Email: strielkowski@prizk.cz
}

\begin{abstract}
This paper constitutes a short introduction to the Proceedings of the $1^{\text {st }}$ International Scientific Conference "Legal Regulation of the Digital Economy and Digital Relations: Problems and Prospects of Development" (LARDER 2020) that was organized by the Prague Institute for Qualification Enhancement in Prague, Czech Republic, on the $22^{\text {nd }}$ and the $23^{\text {rd }}$ of October 2020 and brought together researchers and stakeholders from the fields of law, economics, information and communication technologies (ICT), management and marketing, social sciences, as well as the representatives of the executive and legislative authorities, local self-government, judges, lawyers, managers, and specialists of legal services of enterprises, commercial organizations, postgraduates and undergraduates majoring in law and information and communication technologies. The paper summarizes the main provisions of the conference and outlines its main objectives and provisions.
\end{abstract}

Keywords: digital economy, digitalization, digital relations, legal regulations, policy implications.

\section{INTRODUCTION}

Recent ongoing COVID-19 pandemic had many adverse and grim effects on the world economy as well as on the lives of the people around the planet. Sadly, many people died in hospitals and homes as a result of the unexpected disease for which no cure yet exists. Many businesses went bankrupt and out of existence due to the anti-coronavirus measures that included lockdowns, social distancing, and stopping all forms of travel and hospitality, such as international tourism, as well as entertainment and services, such as hairdressers, restaurants, bars, fitness centres, clubs, and many more.

Nevertheless, together with all its negative aspects, the pandemic had one positive side - it showed the humanity how important might be the digital economy and the digital relations in the $21^{\text {st }}$ century [1]. Thanks to the information and communication technologies (ICT) and the Internet, people could stay in touch while practicing social distances locked up in their homes, continue working remotely using online meetings and teleconferencing as a part of the home office, and even conduct online teaching using various specialised tools such as webinars and learning management systems (LMS) [2].
However, while the digital economy and digital relations are becoming more ubiquitous and mundane as they replace the traditional arrangements, the big issue with their legal regulation remains. Therefore, there is a pressing need to tackle this issue and to try to search for the solutions and new pathways. All of the above was the scope of the $1^{\text {st }}$ International Scientific Conference "Legal Regulation of the Digital Economy and Digital Relations: Problems and Prospects of Development" (LARDER 2020) that was held in Prague, Czech Republic, in October 2020.

The Conference was the first of its kind but it also built upon the whole array of similar events following the $1^{\text {st }}$ International Conference "Social, economic, and academic leadership for the future sustainable development of business and education" which was organised in Prague in 2017 (see Strielkowski and Chigisheva 2018 [3]) and succeeded by the conferences on the same topic held in 2018 and 2019 resulting in interesting and widely cited conference proceedings published by Atlantis Press (see e.g. Strielkowski 2018; or Strielkowski 2019) [4, 5].

It is obvious that LARDER 2020 conference opened up many relevant and interesting topics that are worth looking into and investigating further. The organizers genuinely hope that these Proceedings would become an inspiration and a source of valuable material for any researchers, practitioners, businessmen, or stakeholders working in the field of digital economy and digital relations. 


\section{MAIN TRACKS OF THE LARDER 2020 CONFERENCE}

The $1^{\text {st }}$ International Scientific Conference "Legal Regulation of the Digital Economy and Digital Relations: Problems and Prospects of Development" (LARDER 2020) that was organised in Prague by the Prague Institute for Qualification Enhancement amidst the COVID-19 pandemic in October 2020 consisted of virtual keynote presentations, online oral presentations and poster presentations held in sessions on specific topics. All presentations were met with a great enthusiasm and interests. Long Internet-based discussions and debates followed.

After a long and cumbersome selection of papers submitted to our conference, those that were found to be in accord with rigorous academic and ethical publishing standards, underwent a double-blind peer review. Overall, 45 papers were selected for publication in a form of online proceedings with the renown international academic publisher Atlantis Press. The selected papers represent several fields. However, all of them have one unifying topic represented by the very relevant and novel trends in the legal regulation of the digital economy and digital relations.

All the papers were collected and put into the seven main conference tracks following thematically related areas. This arrangement helped the organizers to place the contributions into the clusters that would not overlap and would fit together nicely. The overall final structure of the Proceedings from the LARDER 2020 Conference can be presented as arranged along the seven main tracks listed below:

- Development of the digital economy and digital relations;

- Civil law regulation of the digital economy and digital relations;

- Administrative responsibility for violations in digital relations;

- Criminal liability for violations in digital relations;

- Topical problems in digital economy and digital relations;

- Digital economy and digital energy security;

- Public administration, e-government, and digitalization.

\section{CHALLENGES OF THE DIGITAL ECONOMY AND DIGITAL RELATIONS}

The digital economy triggered off and is likely to continue to pose numerous challenges for the various areas of European Union economy and society covering its legal base. The phenomenon of digitisation has led to regulatory and enforcement initiatives at EU level and the Digital Markets EU conference organised by the European Commission's Directorate-General for Economic and Monetary Affairs (DGEMA) is an important step towards unravelling these challenges and clarifying the initiatives, enforcement measures and developments discussed above $[6,7]$. Our conference participants touched upon various issues of digitisation, focusing on the challenges faced by regulators, legislators and the judiciary in the design, application and interpretation of laws in Russia, European Union, and all around the world. LARDER 2020 conference therefore addressed the legal issues of regulating the digital economy and implementing regulatory and enforcement measures in a wider context. With regard to this, one has to note that there are no specific laws that have been passed to regulate digital platforms, but there are already laws that cover some aspects of the regulation of digital platforms that are already covered by legislation of single countries, such as, for example, the European Digital Market Regulation Act (EMRA). Existing laws that indirectly regulate the digital economy worldwide were not adopted to regulate the world economy and are therefore not applicable in a plethora of cases and occasions.

However, one can see that the Digital Single Market offers many potential benefits. There are certainly cases where the right of consumers to obtain a contact lens prescription, recognition of digital signatures, a ban on the sale of digital products and services that violate state law, and regulation of wireless Internet services are involved. In this respect, the model adopted by the EU Member States to adequately address the digitisation of economic law as a phenomenon could well be the first step in the development of a legal framework for regulating the collaborative economy [8]. Various researchers deal with a number of different views of this phenomenon, for example in relation to the sharing economy, and attempts to regulate it could violate both international law and the European Convention on Human Rights. In our conference, we discussed (among all) the problems that arise from the legal basis that could be used for sectoral rules relating to the sharing economy, and dare to look at possible best practice examples arising from platforms in this novel industry, and the role of law in its development.

Hence, legal regulations of the digital economy represent an important issue, as consumer data protection and privacy are key factors that need to be taken into account and developed in the context of the development 
of the collaborative economy and its legal framework. Data in a digital economy is important not only for privacy protection, but also for data security and security. Although the benefits of new technologies and trade models are immense, new technologies also pose new risks due to privacy, security and ethical concerns, including autonomous systems that make decisions, for example in autonomous vehicles.

Digital transformation can also lead to the development of monopolies and concerns, creating barriers to competition, for example in the area of data protection and data security. Traditional industries are being destroyed, and the differences between industries and sectors are blurring as technology companies move into new business areas such as information technology, healthcare, education, and health care.

It is not inconceivable, therefore, that the emergence of the digital economy and digital markets will challenge the existing long-standing and sometimes inflexible legal systems. What adjustments need to be made to the current regulatory and enforcement framework and how should each be delineated? In the digital age, the law is proof lasting, but adjustments are needed to function within the current regulatory or enforcement framework.

\section{CONCLUSION}

All in all, it is clear that in a rapidly changing knowledge-based economy, digital skills drive the organisation's competitiveness, innovation and capacity. Therefore, it is important to find legal measures to identify, measure and regulate these skills.

The main objective of this introductory paper was present the aims and objectives of the LARDER 2020 conference which allowed its organizers and participants to examine the role of digital aspects in developing the skills of knowledge workers and to create a conceptual dimension and key operational components that target them. Although these skills are considered crucial, we define a digital aspect integrated with $21^{\text {st }}$ century skills as a key component of a knowledge worker's skills.

Interactive experiences, tools and technologies are advancing and will be further advanced, which will require new scenarios and changing attitudes. Therefore, it becomes important to maintain the appropriate tools for the user experience. People working in the digital economy sector today face opportunities that can turn them into innovators for the products and technologies of the future. Thence, the research of the legal regulation of the digital economy and digital relations in the $21^{\text {st }}$ century are relevant for the future development of the economy and society and need to be disseminated and promoted among the wider audience.

\section{REFERENCES}

[1] W. Strielkowski, COVID-19 Pandemic and the Digital Revolution in Academia and Higher Education, Preprints (2020) 2020040290. DOI: https://doi.org/10.20944/preprints202004.0290.v1

[2] S. Williams, C. Armitage, T. Tampe, K. Dienes, Public perceptions and experiences of social distancing and social isolation during the COVID-19 pandemic: A UK-based focus group study, BMJ Open 10(7) (2020) e039334. DOI: https://doi.org/10.1136/bmjopen-2020-039334

[3] W. Strielkowski. O. Chigisheva (eds.), Leadership for the Future Sustainable Development of Business and Education, Springer Proceedings in Business and Economics. Springer, Cham (2018) 672 DOI: https://doi.org/10.1007/978-3-319-74216-8

[4] W. Strielkowski (ed.), Proceedings of the 2nd International Conference on Social, Economic and Academic Leadership (ICSEAL 2018), Atlantis Press, ASSEHR, 217(2018). https://www.atlantispress.com/proceedings/icseal-18 (accessed 20.01.2021)

[5] W. Strielkowski (ed.), Proceedings of the 4th International Conference on Social, Business, and Academic Leadership (ICSBAL 2019), Atlantis Press, ASSEHR, 359(2019). https://www.atlantispress.com/proceedings/icsbal-19 (accessed 20.01.2021)

[6] B. Aho, R. Duffield, Beyond surveillance capitalism: Privacy, regulation and big data in Europe and China, Economy and Society 49(2) (2020) 187-212. DOI: https://doi.org/10.1080/03085147.2019.1690275

[7] I. Senatori, The European Framework Agreement on Digitalisation: a Whiter Shade of Pale? Italian Labour Law e-Journal 13(2) (2020) 159-175.

[8] W. Ringe, R. Christopher, Regulating Fintech in the EU: the Case for a Guided Sandbox, European Journal of Risk Regulation 11(3) (2020) 604-629. DOI: https://doi.org/10.1017/err.2020.8 